\title{
REFLEXÕES SOBRE RESPONSABILIDADE POLÍTICA E SOCIOCULTURAL DOS MAGISTRADOS $^{1}$
}

\author{
José Alcebíades de Oliveira Junior
}

\section{RESUMO}

Este artigo procura dar prosseguimento às nossas pesquisas sobre Sociologia Judiciária, entendida como aquela passível de ser oportunamente aplicada a aspectos organizacionais (acesso à justiça, morosidade) e aspectos hermenêuticos do Poder Judiciário. Nesse sentido, aborda questões de legitimidade desse poder, bem como questões de responsabilidade política e sociocultural dos magistrados, procurando discutir, ao fim e ao cabo, o percurso mais adequado para decisões judiciais em sociedades pluralistas complexas, nas quais há que se atentar para um conjunto de valorações paradigmáticas ligadas às pessoas humanas, as diferentes culturas, as instituições, ao meio ambiente, aos portadores de deficiência, às questões de raça, etnia, gênero, idosos, adolescentes, etc.

Palavras-chave: Magistrados. Poder Judiciário. Responsabilidade política. Responsabilidade sócio-cultural.

\section{SOBRE LEGITIMIDADE DEMOCRÁTICA (DE ORIGEM, FUNCIONAL E CONSTITUCIONAL) DO PODER JUDICIÁRIO E PRIMEIRAS OBSERVAÇÕES SOBRE RESPONSABILIDADE POLÍTICA ${ }^{3}$}

Consoante Luis Esteban Delgado del Rincón ${ }^{4}$, desde os primórdios do constitucionalismo, por influência francesa um modelo de justiça burocrática foi implantado, de juízes não eleitos, que passam a formar um corpo de funcionários, profissionais do Direito, como diria Max Weber, a quem se encomenda a função de aplicação da lei.

Diante da ausência de uma legitimidade democrática de origem, se busca socorro a uma legitimidade democrática ancorada na função de aplicação da lei democrática, a qual, segundo Luis Esteban, se atribuirá o nome de legitimidade de exercício ou legitimidade funcional ${ }^{5}$.

Esse tipo de legitimidade predominante no Estado liberal fermentou quase que um credo de que o juiz deveria limitar-se exclusivamente a aplicação mecânica da lei, mediante processos mentais estritamente lógicos. E aqui, talvez, não para absolver Hans Kelsen da "culpa" que muitas vezes Ihe é atribuída por pregar uma ciência jurídica sem alma, se encontre boa dose de explicações contextuais para o seu empenho na construção de sua teoria pura do Direito.

Durante o Estado social e democrático, como prossegue o autor espanhol que estamos trabalhando, aumenta consideravelmente a intervenção dos juízes no processo de produção do Direito. Na hora de aplicar uma norma ao caso concreto se 
convertem em verdadeiros "criadores" diretos do Direito, já que gozam de certa discricionariedade na interpretação dos diferentes sentidos que aquela possa ter, aportando assim certo valor que acrescenta na cadeia de produção ou inovação do ordenamento jurídico. Está-se, portanto, diante da jurisprudência como fonte direta do Direito, que estabelece critérios jurídicos gerais vinculantes para os juízes e tribunais, transparecendo estar acontecendo uma verdadeira revisão entre os muros da civil law e da common law.

Diante disso, se coloca então o interrogante bastante atual de como se legitima democraticamente o Direito assim criado pelos juízes? Como saber se as normas criadas refletem efetivamente a vontade do povo? Quem controla os juízes e quem controla os controladores são questões imediatamente decorrentes.

Com efeito, e de fato como temos dito em vários trabalhos ${ }^{6}$, há um novo protagonismo dos juízes no Estado democrático, que agora podem atuar por critérios de oportunidade ou mesmo de justiça social, e não apenas por critérios estritos de legalidade.

$\mathrm{Na}$ análise de Luis Esteban ${ }^{7}$, pode-se observar, num primeiro momento, que frente aos riscos de uma politização subjetiva na Espanha e podemos afirmar que também no Brasil, existem mecanismos que podem ser entendidos como sistêmicos, dentre os quais, os recursos legalmente estabelecidos e a exigência de uma responsabilidade judicial pessoal; porém, como coloca e nos parece essencial, hoje em dia há que se considerarem mecanismos extra-sistêmicos, dentre os quais a "opinião pública", fenômeno nada homogêneo e nada fácil de ser tratado, mas que seguramente é muito real em sociedades democráticas, devendo ser considerado, tal como veremos.

De toda a sorte, como diz Luis Esteban ${ }^{8}$, se no sistema anglo-saxão norte americano ainda existe legitimidade originária pelo voto, é preciso dizer que também esse sistema não está isento de inconvenientes, podendo nele haver ainda em maior grau politização subjetiva do juiz, além desse sistema não garantir capacidade técnica.

Quanto aos países que adotam o sistema continental, como é o caso do Brasil, consoante Esteban ${ }^{9}$ o que é preciso ter presente é que se reconhece o princípio de legitimidade democrática a todos os poderes do Estado, e, fundamentalmente, que a postulação do princípio geral de legitimidade democrática como fundamento da atuação dos poderes do Estado, implica a existência de um marco de garantias, procedimentos e controles previstos na Constituição, que constitui elemento inseparável da essência do princípio democrático para assegurar a autenticidade da vontade popular.

A Constituição, portanto, mantém e sofistica o império da lei na atuação judicial. Obviamente, não de uma maneira mecânica, porém, longe de se poder falar em uma liberdade absoluta, o que conduz ao polêmico e empolgante tema do ativismo judicial (e suas desconfianças). Por isso, como temos escrito em vários lugares, há um interesse cada vez maior de elaboração de uma teoria do Direito desde o paradigma constitucional de Estado na modernidade, como, aliás, fazem Luigi Ferrajoli, Ronald Dworkin, Robert Alexy e Jürgen Habermas. 
Por tudo isso é que a legitimidade de origem ou funcional também pode ser classificada como legitimidade constitucional, no sentido de que é a própria Constituição que em última instância legitima a origem dos juízes e o exercício de suas funções ${ }^{10}$.

\section{QUESTÕES ESPECÍFICAS DE RESPONSABILIDADE POLÍTICA DO PODER JUDICIÁRIO NO EXERCÍCIO DE SUA FUNÇÃO}

A partir do quadro descrito e procurando ir direto ao nosso assunto, estaria o Poder Judiciário submetido como os demais poderes a uma responsabilidade política? Certamente, a resposta é muito complexa.

Partamos, conjuntamente com Luis Esteban ${ }^{11}$, de um conceito de responsabilidade política em sentido amplo e que poderia ser aplicado ao Poder Judiciário: "se entende por responsabilidade política a sujeição dos juízes ao poder político mediante o controle que este pode ter sobre a nomeação e a confirmação dos juízes, sobre o exercício concreto da atividade jurisdicional, sobre a promoção profissional, ou também, sobre a gestão dos instrumentos de responsabilidade disciplinar".

Em princípio, embora a complexidade do sistema jurídico brasileiro permita muitas interpretações (como, por exemplo, a de qual o papel do $\mathrm{CNJ}$ ), parece não existir esse tipo de responsabilidade. No entanto, salvo melhor juízo, vários elementos podem demonstrar o caráter político da atividade judicial, aos quais seria interessante atentar, conforme salienta Esteban ${ }^{12}$ :

1- A avaliação das condutas ou comportamento dos juízes pode ser segundo critérios de oportunidade e não de estrita legalidade;

2 - O caráter político do órgão ante o qual se depura a responsabilidade (CNJ, p.ex:), podendo a responsabilidade ser exigida em última instância pela opinião pública;

3 - O caráter também político do juízo ou procedimento que se para fazer a (sentença) efetiva;

4 - A perda do cargo ou a obrigação de demitir como elemento negativo ou sancionatório, é característico de uma responsabilidade política institucional.

Como ilustração, nos países da common law que adotaram a justiça profissional, os juízes permanecem no cargo enquanto não violem o princípio constitucional do bom comportamento, caso contrário, existem mecanismos que permitem os enquadrar dentro de um tipo de responsabilidade política judicial, ao reunir-se alguns dos caracteres que se acabam de enunciar.

Porém, existem muitas críticas a esses processos, pela intervenção de órgãos políticos, não jurisdicionais, a partir de conceitos amplos e vagos. $E$, ainda, há quem diga que ao final esse mecanismo anglo-saxão atua mais desde um paradigma 
jurídico do que político. Enfim, essa responsabilidade política judicial não vige nos países do sistema continental europeu, como é o nosso.

A questão para debate que permanece é: em que medida um sistema de responsabilidade política judicial resultaria contrário aos princípios constitucionais de independência judicial e inamovibilidade, por exemplo, que supõe a submissão exclusiva do juiz ao império da lei, excluindo que qualquer outro poder do Estado controle o modo como o Juiz exerce sua função? ${ }^{13}$

\section{A RESPONSABILIDADE "POLÍTICA DIFUSA" OU "SOCIAL E CULTURAL" DO PODER JUDICIÁRIO: A CRÍTICA DA OPINIÃO PÚBLICA AO EXERCÍCIO DA FUNÇÃO JUDICIÁRIA}

Este tipo de responsabilidade, como nos mostra Esteban ${ }^{14}$, que guarda relação com a responsabilidade política institucional, tendo o povo como sujeito controlador da função jurisdicional, se caracteriza principalmente pelo submetimento da função judicial ao controle da opinião pública e pela ausência de imposição de uma sanção política ou jurídica como a perda do cargo.

Trata-se de uma responsabilidade conectada com a faculdade dos cidadãos e dos meios de comunicação social para emitir juízos críticos sobre as atividades realizadas e as resoluções ditadas pelos juízes magistrados.

A questão imediata é: que papel joga essa crítica na atuação dos poderes públicos, mesmo sendo um controle indireto de suas ações?

Aqui, procurando estender as reflexões sobre os questionamentos do pesquisador espanhol, vale dizer que autores como Jürgen Habermas ${ }^{15}$, dentre outros com os quais concordamos, acredita firmemente que o posicionamento crítico poderá traduzir-se em uma melhora do funcionamento dos serviços públicos e, em concreto, do funcionamento da administração da Justiça. Além do que, como salienta Esteban, é preciso atentar também, que a emissão de juízos críticos tem seu fundamento nos Direitos constitucionais de liberdade de expressão e informação.

Avançando um pouco mais com Habermas, como é do conhecimento acadêmico esse autor tem trabalhado ao longo dos anos com um conceito para ele chave às sociedades modernas que é o de "esfera pública". Tal conceito, bem mais amplo do que a visão circunscrita à tradicional dicotomia que identifica o público com o Estado e o privado com a sociedade civil, perpassa e procura interligar a ambos, o que tem lhe permitido trabalhar com o que denominaria de "subjetividade coletiva", enquanto um conceito idealmente agregador dos interesses coletivos maiores, e que tem feito avançar não só os Direitos em particular, senão que também as formas mais amplas e estruturais das organizações sociais que se pretendem democráticas. E é nesse sentido que uma possível construção de uma subjetividade pública deva estar identificada com a opinião pública, que, apesar das dificuldades conceituais e materiais, permitiria se trabalhar com a idéia de interesses gerais dos cidadãos, que em última análise são a quem de fato se devem prestar as contas relativas ao tema da soberania. Certamente, os problemas e dificuldades de tornar real essa idéia são 
muitos, mormente quando se assiste a expansão gigantesca do sistema midiático e sua influência, para o bem ou para o mal, na construção da opinião pública.

Voltando ao professor espanhol, ademais de ser um importante Direito fundamental à possibilidade de manifestação da sociedade civil, os ordenamentos jurídicos também ao reconhecerem certos princípios de caráter processual como os de publicidade e oralidade das atuações judiciais bem como o de motivação das sentenças, têm facilitado à participação popular e o controle dos seus atos.

A Justiça Espanhola já se manifestou no sentido de que a publicidade das atuações judiciais tem por finalidade proteger as partes de uma justiça subtraída ao controle público, assim como também manter a confiança nos tribunais, e acreditamos que no Brasil, pelo menos, o debate esteja posto, pois temos assistido casos paradigmáticos dessa relação entre o Poder Judiciário e demais órgãos essenciais à Justiça com a imprensa, tal como o recentíssimo caso Isabela, o que pretendemos pesquisar mais detidamente em breve. Alem do que, como temos presente, é claro que sobre essa publicidade recaem restrições de vários matizes (penais, sobretudo de privacidade), que transcendem nossa abordagem de agora.

Porém, cabe dizer ainda com Esteban ${ }^{16}$ que a relação com a mídia é complexa e poderá redundar até mesmo em coação da liberdade decisória dos juízes. O autor espanhol refere-se aqui aos "processos midiáticos" ou "juízos paralelos" realizados pelos meios de comunicação, e dos quais temos fartura de exemplos no Brasil, como é o caso Isabela que referimos a pouco, e também como Boaventura Santos faz menção em sua obra ${ }^{17}$.

Sobre essa responsabilidade política difusa ou social do Poder Judiciário e dos magistrados, cabe dizer que o principal problema que afeta esse instrumento de fiscalização social da jurisdição, desde o ponto de vista de sua eficácia ou operatividade, é a falta do elemento sancionatório (reeleição, perda do cargo, promoções, etc.), tanto na Espanha quanto no Brasil.

Não obstante isso é nosso ponto de vista de que o importante para a formação dos juízes pode ser encontrado na percepção de que não vivem apartados da sociedade. Não existe em um horizonte mais largo, duas intersubjetividades distintas ou descoladas, que seria a do judiciário e a da sociedade. Muito embora as especificidades e diferenças se faz cada vez mais necessário trabalhar também com suas linhas de contato, sob pena de padecer a legitimidade de um poder da importância do Judiciário. E mesmo correndo algum risco sobre a afirmação que faremos a seguir, sobre esse ponto somos - pelo menos idealmente -, muito próximos a Habermas: a aprovação popular é fundamental para a legitimidade e afirmação da instituição judicial como um todo.

Com efeito, se a sociedade e os Direitos evoluem, o que poderia ser lembrado pela teoria das gerações de Direitos ${ }^{18}$, as instituições necessitam acompanhar e enfrentar os paradoxos decorrentes dos interesses próprios às transformações do Estado e dos Direitos. Daí a importância, pois, de se tentar pensar um modelo adequado para magistrados atuarem nas sociedades complexas, sendo a proposta de François Ost e as teorias da argumentação jurídica, como veremos caminhos 
inevitáveis da busca de uma solução para os problemas jurídicos enfrentados pelo Poder Judiciário.

\title{
4 SOBRE MODELOS DE JUIZ E TEORIAS DA DECISÃO JUDICIAL
}

Por tudo o que foi dito sobre a complexidade e as responsabilidades da função judicial é que julgamos oportuno trazer alguns comentários sobre possíveis modelos de juiz, discutidos pelo prof. Belga François $\mathrm{Ost}^{19} \mathrm{e}$ denominados de Júpiter, Hércules e Hermes para, logo após, considerando Ricardo Lorenzetti, trazer alguns aspectos que julgamos importantes das denominadas teorias da decisão judicial, para, então, culminar com algumas reflexões de Jürgen Habermas sobre teoria da argumentação jurídica.

O primeiro modelo sugerido por Ost seria Júpiter, modelo clássico positivista e que continua ainda sendo ensinado nas Faculdades. Sua base é a codificação - visa a uma racionalização formal e implica numa simplificação radical do material jurídico. Poderíamos detectar nele as seguintes características: monismo jurídico, monismo político ou soberania estatal, racionalidade dedutiva e linear, e uma concepção de tempo orientado para um futuro controlado.

O segundo, Hércules - modelo pós-positivista - lembre-se aqui de Ronald Dworkin, que segundo Ost seria a de um Juiz que se desdobra em "engenheiro social". A questão já não é: "qual o meu dever?", senão "que probabilidade há de que uma jurisdição sancione meu comportamento?"

Uma citação de Ost sobre a realidade que teria de enfrentar um juiz do modelo dworkiano, nos parece muito ilustrativa e merece ser colacionada:

\begin{abstract}
Nada nunca será perdoado ao Juiz assistencial de hoje. Conciliar as economias familiares em crise; dirigir as empresas em dificuldades evitando, se possível, a falência; julgar se corresponde ao interesse da criança ser reconhecido por seu pai natural se a mãe se opõe, apreciar se a interrupção voluntária da gravidez se justifica pelo "estado de angústia" da mulher grávida, intervir no calor dos conflitos coletivos de trabalho e decidir (em procedimento de extrema urgência em um catorze de agosto à meia noite) se a greve dos pilotos aéreos da companhia nacional, prevista para o dia seguinte às seis horas, é lícita ou ilícita(...) julgar se o véu islâmico é compatível com a disciplina e o espírito da escola, etc.,etc. ${ }^{20}$
\end{abstract}

E diante das dificuldades bastante palpáveis dos dois primeiros modelos de juízes, Ost propõe então um terceiro, que seria o juiz Hermes. Creio que da leitura de Ost e também de nossas próprias pesquisas, neste último caso não daria para se falar ainda de um modelo. Trata-se por ora ainda de se trabalhar com diagnósticos sobre como deveria ser esse juiz que, segundo Ost, poderia ser um mediador, comunicador, cuja lei mais importante é a da circulação dos discursos, com a qual arbitra os jogos sempre recomeçados.

Ora, como se vê, o professor Ost sintetiza com seus modelos o desenvolvimento moderno da teoria jurídica que conduz do auge e da crise do REVISTA DO DIREITO UNISC, SANTA CRUZ DO SUL № 33 | P. 68-82 | JAN-JUN 2010 
positivismo jurídico às teorias da argumentação jurídica, e seu debate com as teorias hermenêuticas.

No que tange às teorias da argumentação jurídica, um dos autores que têm se destacado é Neil Maccormick, que trabalhamos em nosso Sociologia Judiciária ${ }^{21}$ e que procura associar uma visão renovada do positivismo com as novas teorias pragmáticas e conseqüencialistas da argumentação jurídica, a qual fala da existência de casos fáceis e casos difíceis no Direito, nomenclatura que Ricardo Lorenzetti adota em sua obra, ao enfrentar esse debate ${ }^{22}$ em sua discussão sobre teoria do Direito na "era da desordem".

E dentre suas colocações, interessante reproduzir aqui alguns caracteres sintetizados por esse autor sobre a teoria da argumentação, como "a existência de um amplo campo para o intérprete e o aplicador do direito conferiu a este a tarefa de protagonista da história. Contudo, já não é tão simples sustentar que a sua tarefa se limita a identificar uma situação de fato e subsumi-la em uma norma. Pelo contrário, deve argumentar frente ao caso utilizando a norma como um instrumento a mais"23. E como segue Lorenzetti, "as principais características da tese da argumentação jurídica são as seguintes":

\footnotetext{
- o direito é uma ciência de problemas e não meramente especulativa; - a tarefa do juiz é o exercício da prudência e não a especulação;

- a prudência é baseada no raciocínio argumentativo;

- argumentar é convencer um auditório imaginário, ou seja, a quem é destinada a decisão;

- a argumentação é baseada na experiência prévia acumulada (tópicos), ou na capacidade do argumento para persuadir um auditório universal utilizado como modelo. ${ }^{24}$
}

Caberia invocar Habermas neste momento, pois ao trabalhar com a teoria da argumentação jurídica, contribui expressamente para o entendimento da noção de argumento:

O conceito de argumento é de natureza pragmática: para saber o que é um "bom argumento", é preciso descobrir o papel que ele desempenha no interior de um jogo de argumentação, isto é, saber até que ponto ele, seguindo as regras desse jogo, pode contribuir para a solução do problema da aceitabilidade ou não-aceitabilidade de uma pretensão de validade controversa. O conceito amplo de uma racionalidade procedimental, abrangendo a dimensão pragmática de uma disputa regulada entre argumentos, permite complementar as características semânticas dos argumentos através das propriedades indiretamente constitutivas da validade de um arranjo, no qual se atualiza o potencial da motivação racional que os bons argumentos carregam consigo. A fresta da racionalidade que surge entre a força meramente plausibilizadora de um único argumento substancial ou de uma seqüência incompleta de argumentos, de um lado, e a incondicionalidade da pretensão à única decisão correta, de outro lado, é fechada idealiter(idealmente) através do procedimento argumentativo da busca cooperativa da verdade. ${ }^{25}$ 
Contudo, como se percebe, a reflexão de Habermas aduz mais claramente ingredientes de uma teoria do discurso para a argumentação, bem como elementos de uma democracia procedimentalista e deliberativa, o que, embora a importância, transcende nossos interesses momentâneos. ${ }^{26}$

Outrossim, embora estejamos conscientes de que epistemologicamente falando Ost propõe certa ontologia peculiar ao Direito, e que Habermas fala mais desde um ponto de vista procedimental desse fenômeno, acreditamos que ambos propõe como fundamental aos poderes de Estado, a defesa da soberania popular no âmbito da complexidade institucional reinante, bem como, a atribuição de importância em se dar a palavra a todos os participantes de um determinado cenário conflitivo que envolva interesses públicos. Com efeito, voltamos a insistir com uma afirmação que nos parece lapidar: como diria Habermas e foi salientado por Jessé Souza no Brasil, "ao poder comunicativo da sociedade é preciso estender o poder administrativo" 27 .

De modo que a consciência de que nas sociedades complexas existe uma multiplicidade de atores jurídicos, uma imbricação sistemática das funções e multiplicação dos níveis de poder, modificações substanciais nas modalidades da ação jurídica, como afirma Ost, é fundamental para a construção de um modelo de juiz que dê conta adequadamente das expectativas sociais. Enfim, a sociedade global e multicultural de hoje em constante mudança e novas informações, requer formação continuada de todos aqueles que pretendam se legitimar como elite política e jurídica.

\section{CONCLUSÃO}

Como corolário do que foi dito, gostaríamos de trazer uma reflexão final sobre teorias de decisão judicial, com obra recentemente traduzida no Brasil do Ministro da Suprema Corte Argentina, Ricardo Luis Lorenzetti ${ }^{28}$.

Pelo que pudemos depreender da experiência desse pesquisador, que associamos ao pesquisador espanhol e ao pensador alemão, pode-se dizer que vivemos hoje na área do Direito uma "era da desordem". Paradigmas positivistas, moralistas ou de qualquer outro matiz tem sido insuficientes para fundamentar as decisões judiciais. Assim, segundo esse pensador e cremos que de alguma forma também pensamos de modo semelhante, os juízes tem de recorrer a visões mais amplas de compreensão das sociedades pluralistas, tomando em consideração, nas palavras desse juiz, os diversos paradigmas que se vão construindo, não os negando e se possível os colocando em contato. Dentre eles, salienta, por exemplo, a importância de uma consideração nas sentenças de um paradigma de acesso aos "bens jurídicos primários", um paradigma "protetivo" dos hiposuficientes nas sociedades capitalistas de consumo, um paradigma "coletivo" que defenda os interesses de toda a coletividade, um paradigma "conseqüencialista", um paradigma "constitucionalista", um paradigma "ambientalista", etc.

Com efeito, a proposta do professor Lorenzetti além de descritivamente correta, serve efetivamente para chamar a atenção de que quando falamos em sociedades pluralistas complexas, estamos a nos referir a uma nova conjuntura que reúne não 
só a ampliação do número de sujeitos de direitos, como também uma ampliação bastante elevada dos pontos de vista culturais que unem essas comunidades, formadas muitas vezes por diferenças de raças, etnias, gênero, idades, portadores de deficiência, etc.

Como ressalta Lorenzetti ${ }^{29}$, "em sociedades pluralistas cada um tem sua concepção de vida e naturalmente o juiz não escapa dessa regra... Entretanto, o juiz não pode falhar com base na sua própria convicção, pois estará prejudicando a todos que não compartilham do seu ponto de vista", e o como superar essas "armadilhas" é o que tem composto em grande parte o leque de preocupações dos juristas na era do constitucionalismo ${ }^{30}$.

\section{REFLEXIONES SOBRE LA RESPONSABILIDAD POLÍTICA DE LOS JUECES Y SOCIOCULTURAL}

\section{RESUMEN}

Esto artículo intenta dar seguimiento a nuestras investigaciones respecto la Sociologia Judicial comprendida como aquella con posibilidad de ser oportunamente aplicada a aspectos organizacionales (acceso a la justicia, morosidad) y aspectos hermenéuticos del Poder Judicial. En esto sentido, abarca cuestiones de legitimidad de esto poder y cuestiones de responsabilidad política y socio-cultural de los magistrados, objetivando la discusión del sendero más adecuado para decisiones judiciales en sociedades pluralistas complejas, en las cuales hay que tener atención para un conjunto de valoraciones referenciales ligadas a las personas humanas, a las diferentes culturas, a las instituciones, al medio ambiente, a los necesitados de cuidados especiales, a las cuestiones raciales, de etnia, género, ancianos, jóvenes etc.

Palabras-claves: Magistrados. Poder Judicial. Responsabilidad política. Responsabilidad sócio-cultural.

\section{THOUGHTS ON JUDGE'S POLITICAL AND SOCIO-CULTURAL RESPONSIBILITY}

\section{ABSTRACT}

This article search to proceed on our researches about judiciary sociology, understood as the knowledge that could be applied both to organization aspects of Judiciary power (justice access, slowness) and hermeneutic aspects of that power. On such manner, this thoughts works judiciary power legitimacy, judge's political and socio-cultural responsibility, seeking to discuss, to start to end, de most adequate path to think judicial decisions on complex pluralist societies - decisions that must attend to a very complex paradigmatically linked to human being, different cultures, institutions, environment, disabled personal, race, gender, old and young questions. 
Keywords: Judges. Judiciary Power. Political Responsibility. Socio-cultural responsibility.

\section{NOTAS}

1 Texto originalmente elaborado e submetido ao XIX Encontro Nacional do CONPEDI, a ser realizado de 09 a 12 de junho de 2010, na UFC, Fortaleza, Ceará. Versão revista e ampliada para esta publicação, principalmente quanto ao item que trata do debate sobre critérios para as decisões judiciais.

2 Professor Titular da Faculdade de Direito da UFRGS e Professor e Coordenador Acadêmico do Mestrado em Direito da URI - Santo Ângelo/RS. E-mail: josealcebiadesjunior@yahoo.com.br. Endereço: Universidade Federal do Rio Grande do Sul, Faculdade de Direito - Avenida João Pessoa, 80 - Centro - CEP 90040-001 - Porto Alegre, RS - Brasil.

3 Este texto, originalmente se apresentou como uma leitura comentada e adaptada à realidade brasileira do Capítulo 2 da obra "Constitución, Poder Judicial y responsabilidad", de Luis Esteban Delgado Del Rincón, intitulado "La responsabilidad política y social Del poder judicial", p.79-127. Esta versão, acopla com maior ênfase ângulos por nós já retrabalhados em "Sociologia Judiciária", Enfam-STJ, 2010, no prelo, sobre o debate de teorias da decisão judicial. Incorpora, também, aspectos da obra de Ricardo Lorenzetti "Teoria da Decisão Judicial", especialmente sobre características da teoria da argumentação jurídica, além de aspectos da tensão entre faticidade e validade da obra "Direito e Democracia", de Jürgen Habermas.

4 "Constitución...", op.cit. p. 79 e segs.

"Constitución...", op.cit.p. 80.

Conforme "Teoria Jurídica e Novos Direitos", 2000, e "Sociologia Judiciária", 2010 (no prelo).

"Constitucion...", op.cit.p.82.

"Constitucion...",op.cit.p. 83.

"Constitucion...", op.cit.p.86.

"Constitucion...", op.cit.p.91.

"Constitucion", op.cit.p. 92.

"Constitucion...", op.cit. p. 92 e 93.

"Constitución...", op.cit. p. 100.

"Constitución...", op.cit. p. 108.

15 Conforme várias partes de sua obra "Direito e Democracia, entre faticidade e validade", 2 volumes. RJ:Tempo Brasileiro, 1997.

16 "Constitución...", op.cit.p.116

17 "Para uma Revolução democrática da Justiça”, Editora Cortez, 2007. Sobre o tema em específico, Boaventura afirma que no Brasil (e de resto em várias partes do mundo), " plácida obscuridade dos processos judiciais deu lugar à trepidante ribalta dos dramas judiciais". E de fato, há uma cumplicidade entre a mídia e os tribunais, pois como diz Boaventura, "os processos judiciais tiveram sempre o potencial de se transformarem em dramas. De qualquer modo, o que lucidamente conclui Boaventura, é de que "há que se construir uma relação mais virtuosa entre justiça e a comunicação social". "É preciso desenvolver um programa de conhecimento recíproco, que permita impedir a perda de legitimidade, tanto dos tribunais como da comunicação social". Op.cit. p. 83-86.

Ver nosso livro "Teoria Jurídica e Novos Direitos", Rio de Janeiro: Lúmen Júris, 2000.

19 Juizado da Infância e da Juventude - Tribunal de Justiça do Estado do Rio Grande do Sul, Porto Alegre, Departamento de Artes Gráficas, 2003. "Júpiter, Hércules, Hermes: Três Modelos de Juiz", François Ost, op.cit. pp. 109-130. Texto que nos chegou às mãos através do especialista na área, Juiz João Batista Costa Saraiva.

Cfe. "Teoria da Decisão Judicial", op.cit.p. 176 e segs.

Cfe. "Teoria da Decisão Judicial", op.cit.p. 176.

"Teoria da Decisão Judicial", op.cit.p. 176

"Direito e Democracia, entre faticidade e validade". Jürgen Habermas, vol I, p. 283.

26 Sobre Democracia Deliberativa estamos elaborando uma investigação com a finalidade de atender pesquisa registrada junto ao CNPq, na condição de Pesquisador Sênior. 
27 “A modernização seletiva”. Jessé Souza, Brasília: UNB, 2000.

28 "Teoria da Decisão Judicial- Fundamentos de Direito". Ricardo Luis Lorenzetti. Trad. Bruno Miragem, Revisão Cláudia Marques. São Paulo: Editora Revista dos Tribunais, 2009.

29

30 Cabe alertar com Lorenzetti, que dois grandes desafios ao constitucionalismo contemporâneo, podem ser encontrados na globalização e no multiculturalismo. Por um lado, "o termo "globalização" do sistema jurídico se refere especificamente ao surgimento de regras institucionais homogêneas que respondam ao funcionamento de uma sociedade global com a que se observa na atualidade (...)". Entretanto, "O processo de globalização não elimina as particularidades nacionais, nem os blocos culturais regionais. A exposição correta não é a rejeição total, ou a negativa de considerar argumentos alheios. Este problema também existiu no século XIX, e Vélez Sarsfield o resolveu com praticidade e ecletismo, dignos de serem recordados: valeu-se do Código Civil francês, de Aubry e Rau, de Demolombe, mas também de Blackstone. Utilizou obras européias e estadunidenses, mas também recorreu aos latinoamericanos Teixeira de Freitas e Andrés Bello. Não teria subsistido sem essa mistura". Por outro lado, "a América Latina, e principalmente a Argentina, é uma grande mescla cultural, e essa é a sua vantagem comparativa em um mundo que recém está experimentando uma convivência de culturas que entre nós é praticada há muito tempo. Negar este fato seria um erro; daí por que aceitar o ecletismo é o correto", op. cit. pp. 64-65.

\section{REFERÊNCIAS}

AGUIAR. Las garantías constitucionales de los derechos fundamentales en la constitución española. In: Revista de Derecho Politico. v. 10. 1981.

ALEXY, Robert. Sistema jurídico, princípios jurídicos y razón práctica. Texto integrante de trabalho apresentado às IV Jornadas Internacionales de Lógica e Informática Jurídicas, em San Sebastian, em setembro, 1988. Trad. para o espanhol de Manuel Atienza.

ALEXY, Robert. Teoria de la argumentacion juridica. Trad. Manuel Atienza. Marid: Centro de Estúdios Constitucionales, 1989.

ALEXY, Robert. Tres escritos sobre los derechos fundamentales y la teoría de los princípios. Traducido por Carlos Bernal Pulido. Bogotá: Universidad Externado de Colombia, 2003.

ALEXY, Robert. Teoria dos direitos fundamentais. Trad. Virgílio Afonso da Silva. São Paulo: Malheiros Editores, 2008.

ATIENZA, Manuel. As razões do direito. Trad. Maria Cristina G. Cupertino. São Paulo: Landy, 2000.

BARRETO, Vicente. Multiculturalismo e direitos humanos: um conflito insolúvel? In Direitos Humanos e sociedade cosmopolita. Coordenador César Augusto Baldi. Rio de Janeiro: Renovar, 2005.

BAUDRILLARD, Jean. A sociedade de consumo. Trad. Artur Morão. Rio de Janeiro: Elfos Edit. Lisboa: Edições 70, 1995. 
BENJAMIN, Antonio Hermann. "Introdução ao Direito Ambiental Brasileiro". In Cadernos da Pós-Graduação em Direito da UFRGS, vl.2 n.5. POA: PPGDIR/UFRGS, 2004, p.94-105.

BERGOVICI, Gilberto. Soberania e constituição. Para uma crítica do constitucionalismo. São Paulo: Quartier Latin, 2008.

BIELEFELD, Heiner. Filosofia dos direitos humanos. trad. Dankwart Bernsmüller. São Leopoldo: Unisinos, 2000.

BOBBIO, Norberto. A era dos direitos. Trad. Carlos Nelson Coutinho. Rio de Janeiro: Editora Campus, 1992.

BOUCAULT, Carlos E. de Abreu (org.); RODRIGUES, José Rodrigo (org.). Hermenêutica Plural. São Paulo: Martins Fontes, 2002.

BRASIL. SUPERIOR TRIBUNAL DE JUSTIÇA (STJ). Bibliografia básica para o ensino e pesquisa nas escolas de magistratura. Brasília: Enfam, 2008.

CANARIS, Claus-Wilhelm. Direitos fundamentais e direito privado. Traduzido por Ingo W. Sarlet e Paulo M. Pinto. Coimbra: Almedina, 2006.

CANCLINI, Nestor. Diferentes, desiguais e desconectados. Rio de Janeiro: UFRJ, 2005.

CANOTILHO, José Joaquim Gomes. Civilização do Direito Constitucional ou Constitucionalização do Direito Civil? A Eficácia dos Direitos Fundamentais na Ordem Jurídico-civil no Contexto do Direito Pós-moderno. In: GRAU, Eros Roberto e GUERRA FILHO, Willis Santiago (orgs.). Direito constitucional: estudos em homenagem a Paulo Bonavides. São Paulo: Malheiros, 2001.

CARRIÓ, Genaro. Princípios juridicos y positivismo juridico. B.Aires: Abeledo-Perrot, 1970.

DOUZINAS, Costas. O fim dos direitos humanos. Trad. Luzia Araújo. São Leopoldo, Edit. Unisinos, 2009.

DWORKIN, Ronald. Uma questão de princípio. Trad. Luis Carlos Borges. São Paulo: Martins Fontes, 2000.

FERRAJOLI, Luigi. O direito como sistema de garantias. In $O$ novo em direito e política. Organizado por José Alcebíades de Oliveira Junior. Porto Alegre: Livraria e Editora do Advogado, 1997.

HAARSCHER, Guy. A filosofia dos direitos do homem. Trad. Armando Pereira da Silva. Lisboa: Instituto Piaget, 1997.

HABERMAS, Jürgen. Conhecimento e Interesse. Trad. José N. Heck. RJ: Zahar Editores, 1982. 
HABERMAS, Jürgen. Direito e democracia, entre faticidade e validade. 2 vols. Trad. Flávio B. Siebeneichler. Rio de Janeiro: Tempo Brasileiro, 1997.

HALL, Stuart. A identidade cultural na pós-modernidade. Trad. Tomaz Tadeu da Silva e Guacira Lopes Louro. 3. ed. Rio de Janeiro: DP\&A, 1999.

JAYME, Erik. direito internacional privado e cultura pós-moderna. Cadernos do Programa de Pós-graduação em Direito da UFRGS, vol I, no. 1. Porto Alegre: 2003.

KYMLICKA, Will. Ciudadanía multicultural. Trad. Carme Castells Auleda. Barcelona:Editorial Paidós, 1996.

LAFER, Celso. A internacionalização dos direitos humanos. São Paulo: Manole, 2005.

LAFER, Celso. A reconstrução dos direitos humanos, diálogo com o pensamento de Hanna Arendt. São Paulo: Cia. das Letras, 1988.

LAFER, Celso. Análise e Interpretação do Art. 5ํ, XLII, da Constituição de 1988: sobre o alcance e o significado do crime da prática do racismo, uma discussão do caso Ellwanger e da decisão do STF no HC n.82424/RS. In A internacionalização dos direitos humanos. São Paulo: Manole, 2005.

LOPES, Ana Paula de Almeida. A Judicialização do Processo Político e a Politização do Poder Judiciário: Uma análise da Intervenção do STF no processo político partidário. Dissertação de Mestrado em Direito, UNISINOS, 2009, mimeo.

LOPES, José Reinaldo Lima. Moderação e Justiça Constitucional. In Jornal o Estado de São Paulo, caderno A2, Opinião, 20 de março, 2009.

LORENZETTI, Ricardo Luis. Teoria da Decisão Judicial. Fundamentos de Direito. Trad. Bruno Miragem. SP: Edit. Revista, 2009.

MAcCORMICK, Neil. Legal Reasoning and Legal Theory. New York: Oxford University Press Inc, 1994.

MARINONI, Luiz Guillherme. Técnica processual e tutela dos direitos. São Paulo: RT, 2004.

MARQUES, Cláudia Lima. A crise científica do Direito na pós-modernidade e seus reflexos na pesquisa. In: I Conferência Científica do Salão de Iniciação da UFRGS, 1999.

MIGUEL, Alfonso Ruiz. Filosofia e derecho em Norberto Bobbio. Centro de Estudios Constitucionalesm, Madrid, 1983, p.23.

OLIVEIRA JUNIOR. José Alcebíades. Sociologia Judiciária. Enfam-STJ, 2010 (No prelo). 
OLIVEIRA JUNIOR. José Alcebíades(org.). Cultura e Prática dos Direitos Fundamentais. RJ: Lumen Juris - 2009 - 2010.

OLIVEIRA JUNIOR, José Alcebíades de (Org.). Faces do multiculturalismo. Santo Ângelo: Ediuri, 2007.

OLIVEIRA JUNIOR, José Alcebíades de. Repensando o ensino do Direito para sociedades multiculturais. In: Revista da Faculdade de Direito da UFRGS, vol. 25. POA: UFRGS, 2005, p.109-120.

OLIVEIRA JUNIOR, José Alcebíades. Teoria jurídica e novos direitos. Rio de Janeiro: Lúmen Júris, 2000.

OLIVEIRA JUNIOR, José Alcebíades de. (org.). O novo em direito e política. Porto Alegre: Livraria do Advogado, 1997.

OST, François. Júpiter, Hércules, Hermes: Três modelos de Juiz. Trad. Marcia Ribeiro. Juizado da Infância e da Juventude, Tribunal de Justiça-RS, no.17, 2009.

QUADRA-SALCEDO, Tomás. El recurso de amparo y los derechos fundamentales en las relaciones entre particulares. Madrid: Civitas, 1981.

RIBAS FILHO, Thiago. Juizados Especiais e Democracia. In Cidadania e Justiça, Revista da Associação dos Magistrados Brasileiros, ano 2/ํㅡ 5, $2^{\circ}$ semestre/1998, pp. 127-132.

RINCÓN, Luis Esteban Delgado Del. Constitución, Poder Judicial y Responsabilidad. Madrid: Centro de Estudios Políticos y Constitucionales, 2002.

ROCHA, Leonel. Epistemologia jurídica e democracia. 2. versão. São Leopoldo: Unisinos, 2003.

SANTOS, Boaventura de Souza. Para uma revolução democrática da justiça. São Paulo: Edit.Cortez, 2007.

SARLET, Ingo Wolfgang. A constituição concretizada: construindo pontes entre o Público e o Privado. Porto Alegre: Livraria do Advogado, 2000.

SARMENTO, Daniel. (org.). Igualdade, diferença e direitos humanos: perspectivas global e regional. Rio de Janeiro: Lumen Juris, 2008.

SOUZA, Jessé. A modernização seletiva. Brasília: UnB, 2000.

STUDNICKI, Tomasz Gizbert e STELMACH, Jerzy. Law and Legal Cultures in the 21 st. Century. Diversity and Unity. Warszawa: Oficyna, a Wolters Kluwer business, 2007.

TAYLOR, Charles. et alli. (org). A política de reconhecimento. In: Multiculturalismo. Trad. Marta Machado. Lisboa: Instituto Piaget, 1994, p.45-94. 
TORRES, Jesús García. JIMÉNEZ-BLANCO, Antonio. Derechos fundamentales y relaciones entre particulares. Madrid: Civitas, 1986.

TOURAINE, Alain.? Podremos vivir juntos? Iguales y diferentes. Buenos Aires: Fondo de Cultura Econômica de Argentina, 1996.

TREVES, Renato. Sociologia do direito. Trad. Marcelo Branchini. São Paulo: Manole, 2004.

TRIBE, Lawrence. American Constitutional Law. 2nd ed. Mineola: The Foundation Press, 1988. p. 1691. (tradução livre).

UBILLOS, Juan Maria Bilbao. Los derechos fundamentales en la frontera entre lo público y lo privado. Madrid: Mcgraw-Hill, 1997.

VALE, André Rufino do. Eficácia dos direitos fundamentais nas relações privadas. Porto Alegre: SAFE, 2004.

Recebido para publicação: 18/10/2010

Aceito para publicação: 27/12/2010 